\title{
Linx
}

Revue des linguistes de l'université Paris X Nanterre

66-67| 2012

Dynamiques de la construction des sens attendus et inattendus dans les langues

\section{Genre Across the Line: Adaptations, Hoaxes and Misunderstandings}

\section{Flore Coulouma}

\section{(2) OpenEdition \\ Journals}

Electronic version

URL: http://journals.openedition.org/linx/1462

DOI: 10.4000/linx.1462

ISSN: 2118-9692

Publisher

Presses universitaires de Paris Nanterre

\section{Printed version}

Date of publication: 15 September 2012

Number of pages: 175-187

ISSN: 0246-8743

\section{Electronic reference}

Flore Coulouma, « Genre Across the Line: Adaptations, Hoaxes and Misunderstandings », Linx [Online], 66-67 | 2012, Online since 15 September 2013, connection on 19 April 2019. URL : http:// journals.openedition.org/linx/1462 ; DOI : 10.4000/linx.1462 


\title{
Genre Across the Line: Adaptations, Hoaxes and Misunderstandings
}

\author{
Flore Coulouma - UA 370 (CREA GReG) \\ Université Paris Ouest Nanterre la Défense
}

\section{Introduction}

In 1964, the United States Supreme Court overruled a decision by the State of Ohio to ban a French film for obscenity, after local cinema manager Nico Jacobellis was convicted for showing Les Amants by Louis Malle (1958). Jacobellis appealed the decision and took Ohio State to the Supreme Court, claiming his First Amendment right to free speech. The Supreme Court had to determine whether or not the film was pornographic and thus legally subjected to censorship. Judges eventually decided that the film was not "hard-core pornography" and was therefore protected by the Constitution. The now famous trial became textbook history (Gerwitz, 1996) when Justice Potter Stewart made his concluding statement:

I shall not today attempt further to define the kinds of material I understand to be embraced within that shorthand description [hard-cord pornography]; and perhaps I could never succeed in intelligibly doing so. But I know it when I see it, and the motion picture involved in this case is not that.

Justice Steward understood the elusive and contradictory nature of genre: we cannot define it but we use it instinctively and mostly appropriately in our daily lives. In this regard, the judge was - no doubt unconsciously - following Wittgenstein's reflections on meaning and understanding in language: we are using words and 
following rules, but the meaning and "labelling" of things and concepts are not, in fact, preparatory to their use; rather, signification appears through our daily enactment of language games (Wittgenstein, 2001, 1, p. 26-32). The problem with genre is that like other language games, intuitions and uses vary with place and time; the Jacobellis trial is a typical case and a fitting starting point to our reflection on the notion of genre.

In this article, I will argue that the essential difficulty of genre is that it is both a blurry concept and a very familiar one. This article is the result of a keynote speech presented at the Coldoc International Linguistics Conference in November 2013. The conference theme was the question of genre in written and oral discourse. Such a broad concept is variously defined according to theoretical points of view and objectives, but most importantly, the question of genre enables us to reflect on the relationship between the descriptive function of genre categorization in discourse, and the socially prescriptive nature of generic rules in our everyday or recreational language use. My aim here is not to present a definite and exhaustive definition of genre, but rather to raise a number of issues contained in our underlying assumptions on genre, and to examine genre as a discourse categorization intrinsically vulnerable to failure and ambiguity. I will examine two cases of genre misunderstanding in literary and academic discourse: Orson Welles's 1938 radio adaptation of H. G. Wells's War of the World, and Alan Sokal's 1996 "hoax" with the respected academic journal Social Text. Both cases are revelatory of a politics of genre in the academic world and in society as a whole.

\section{Definitions and issues}

Genre is a fuzzy concept with a long and evolving history alternating prescriptive injunctions and investigative descriptions. From Aristotle to the $19^{\text {th }}$ century tradition of literary genre taxonomy, to Bakhtin, Todorov and contemporary linguistics, the notion of genre has been a central concern to many disciplines, of which rhetoric and literary studies are only the tip of the iceberg. My aim here is not to review the entire literature on genre, but instead to present a few definitions from theoretical approaches within the English-speaking literature (cognitive linguistics, systemic functional linguistics, rhetoric, and anthropological linguistics), and to draw from them a number of recurring issues that will then help us examine our specific cases of "genre misunderstanding." In his Cognitive Grammar, Langacker defines genre laconically as "any recognizable type of linguistic production" (2008, p. 478). For Langacker, genres are "based on cultural scenarios representing familiar kinds of linguistic interaction"; a scenario includes a purpose and a specific viewing arrangement, distinct from canonical face-to-face interaction (Ibid. p. 478). This puts genre at the heart of conventional human practices. Similarly, rhetoric professor Carolyn Miller considers genre as "typified rhetorical action" (1984, p. 151), thus further emphasizing the notion of intentional action within a conventional framework of practices, and introducing the notion of stereotype. Martin and Rose, of the Sydney school of systemic functional linguistics, define genres as "staged, goaloriented social processes" (2008, p. 6), crucially suggesting that genres are not definite 
categories but evolving practices. The question of social practices leads us to that of discourse communities. John Swales introduces the notion in his seminal study Genre Analysis:

A genre comprises a class of communicative events, the members of which share some set of communicative purposes. These purposes are recognized by the expert members of the parent discourse community, and thereby constitute the rationale for the genre. This rationale shapes the schematic structure of the discourse and influences and constrains choice of content and style. (1990, p. 58)

While a speech community is a distinct group of individuals whose members share the same norms and functional rules that determine the appropriateness of utterances, a discourse community is sociorhetorical rather than sociolinguistic. It consists of a "group of people who link up in order to pursue objective that are prior to those of socialization or solidarity, even if these latter should consequently occur. In a discourse community, the communicative needs of the goals tend to predominate in the development and maintenance of its discoursal characteristics" (Swales 1990, p. 24). The rules of genre are therefore goal-oriented, with the implicit requirement that individual communicative purposes must fit those of the discourse community, in order to maintain homogeneous genre distinctions. This, of course, is highly unstable in contexts of creative discourse where originality and individuality take precedence over canonical rules.

Finally, let us look at William Foley's anthropological definition of genre. Foley focuses on historical stratification: genres are the result of a building process through "intertextuality," which means that any individual "enactment" of a given genre require the previous acquisition of a culture of genre.

Genres are historically situated ways for constructing and interpreting texts, an interpretive set of principles linking historically transmitted schemes for framing linguistic performances. These frames for interpreting of framing devices are typically dialogic, juxtaposing language drawn from various historical sources, and it is from this intertextuality that much of the power of individual genres derives. (...) Genres do not exist as abstract categories, but only as schemes of interpretation which are enacted in particular performances. (1997, p. 377)

Shared knowledge and the culture of genre bring me to the question of genre literacy: the ability to identify and use genre appropriately in various contexts. Not surprisingly, many linguists working on genre are especially concerned with its applicability in the field of education, through genre learning and genre literacy. Several problems are at stake: from a descriptive point of view, the reality of discourse and the social norms attached to genre are historical and thus subject to change. Thus the emergence, evolution and disappearance of genre categories mean that they cannot be examined as stable concepts. Secondly, if genre literacy is both a language skill and a social skill, how does it work: does our usage-based knowledge of genre rely on family resemblance, on stereotypical models, or both? From a normative point of view, genre is a rule-based game, which makes it a sociologically marked question: the differentiated levels of access to generic norms and standards are signifiers of social status and integration. Although the question of genre has now been fully 
appropriated by linguists and is not solely relegated to the realm of literary criticism whose historical purpose is the assessment and inclusion of emerging works in the corpus of canonical literature - it remains inseparable from issues of normativity. From a meta-linguistic point of view, our use of genre in discourse analysis reveals our perception and, to a certain extent, reproduction of our own social context, hierarchies and dynamics.

Let us now turn to understandings of genre in the English-speaking literary tradition, with a canonical classic of modernist literature: James Joyce's Portrait of the Artist as a Young Man (1916). In Portrait, first-person narrator and Joyce alter ego Stephen Dedalus ponders the meaning of life and the role of the artist, and his own relationship with language. In the following quote, Stephen attempts to define art, and his reflections are particularly relevant to the question of genre:

What I have said (...) refers to beauty in the wider sense of the word, in the sense which the word has in the literary tradition. In the marketplace it has another sense. (...) art necessarily divides itself into three forms progressing from one to the next $(\ldots)$ the lyrical form, the form wherein the artist presents his image in immediate relation to himself; the epical form, the form wherein he presents his image in mediate relation to himself and to others; the dramatic form, the form wherein he presents his image in immediate relation to others. (...) Is a chair finely made tragic or comic? Is the portrait of Mona Lisa good if I desire to see it? If not, why not? (...) If a man hacking in fury at a block of wood, Stephen continued, make there an image of a cow, is that image a work of art? If not, why not? (1996, p. 243-4)

Stephen proposes a generic classification largely inspired by Aristotle and Thomas Aquinas. His remarks raise four important points. First, the question of subjectivity and inter-subjectivity in language: what effectively creates the "mediate relation to [oneself] and to others" in art is its dialogic dimension? Like art, genre is determined by the kind of relationship the speaker/writer/artist maintains with his audience. Secondly, Stephen questions the very notion of category by challenging the validity of stable criteria in generic descriptions of discourses and works of art. Stephen also hints at the importance of cultural contexts: what makes the chair comic or tragic is largely a question of tradition and conventions - or, as Foley puts it, the cumulative, anthropological intertextuality of human practices affects our understanding of the chair. Stephen's third issue, which is also a crucial point of Joyce's novel, is the question of evaluative judgment, bringing us back to appropriateness and the literary canon. Finally, Stephen, who is an aspiring artist, is obsessed with authorial intention and purpose: his anguished questions remind us that authorial purpose is not always felicitous, since the overall meaning and genre of utterances and discourses largely rely on uptake and interpretation. Last but not least, Stephen makes a crucial distinction, in this excerpt, between "beauty" (i.e. art) in the "literary tradition" and beauty "in the marketplace." For Stephen, the marketplace lies outside art and academia, and refers to popular culture - the culture that is consumed by the masses. This is all the more relevant to our analysis as the term "genre" is very commonly used in the Englishspeaking world to distinguish high-brow literature from "genre fiction," i.e. productions of lower aesthetic and intellectual standards but successful and financially profitable. "Genre literature" is a label that goes beyond the practical categories of 
bookselling and marketing to shed light on the notion of genre as a whole. Also called "genre fiction," "popular fiction," "category fiction," or "commercial fiction" in the publishing industry, it reproduces the old distinction between high and low culture, and brings us back to speech communities and social status.

In a humorous 2001 article for the Observer, journalist Robert McCrum attempts to define literature: "What is 'literary fiction'? To many, it's the titles on the short list for the Booker Prize" (2001, online). McCrum goes on to explain his understanding of "highbrow" and calls for an end to the literary versus genre distinction. This widespread distinction goes back to $20^{\text {th }}$ century philosophers Blanchot and Derrida, who claimed that post-modernist fiction and deconstructionism, by putting forward intertextuality and promoting the subversion of traditional conventions, were moving beyond genre (Blanchot 1959, p. 243-4 ; Derrida 1980, p. 55-81). Yet, as Jean-Marie Schaeffer remarked about Blanchot's dismissal of genre, the post-modernists' subversive injunction is equally genre-based (Schaeffer, 1995, p. 627). There is no way out of genericity, but rather a continuum; any text and language production can be classified according to contextual relevance and its engagement with readers/cospeakers" expectations. While the "gente" label is usually restricted to the commercial, "lowbrow" categories of fiction, this can lead to schizophrenic nonsense: contemporary author and Booker Prize winner John Banville has been hailed as one of the best Irish prose authors of his generation, yet he publishes crime fiction under the pseudonym Benjamin Black. This should not imply that the Benjamin Black stories are less worthy of literary attention, or that they are simply marketed for a different, less demanding readership. The following diagram presents another humorous attempt at mapping the genre/literary continuum, with "stuff" corresponding to non-realistic, entirely madeup fiction unrelated to everyday experience, such as space travel and outlandish serial killers (Kardos, 2012, online):

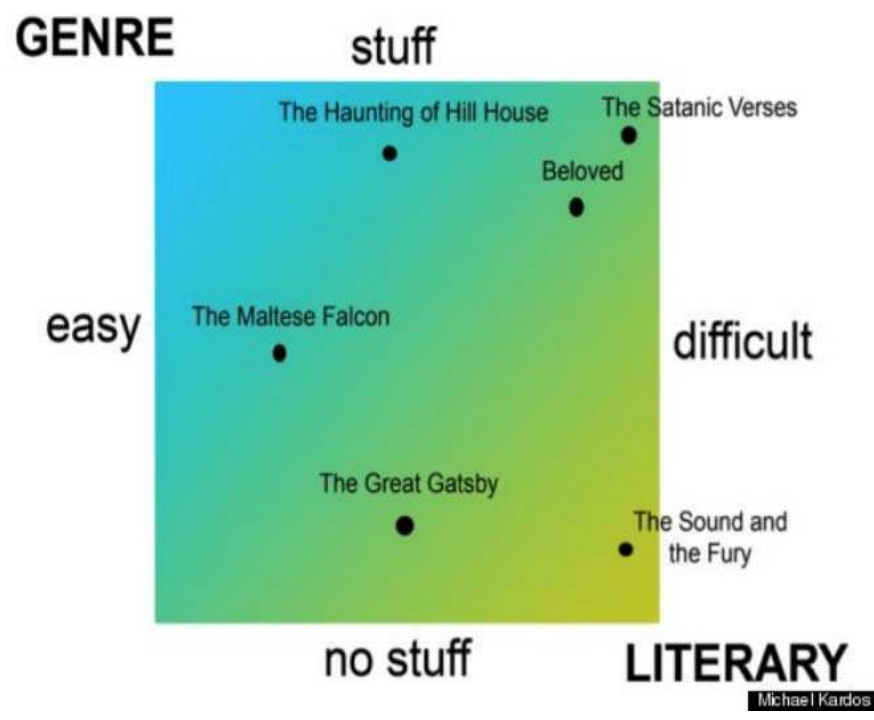


This diagram crucially points to the question of consumption: commercial "genre" fiction is addressed to a specific audience that is a clearly defined marketing target. In that respect, a specific genre must be easily recognizable and relevant to the target in question: it must elicit maximum uptake and minimum cognitive effort from its readership, following Sperber and Wilson's relevance principle (2004, p. 610). This brings us back to the function of stereotypes and formulaicity in genre recognition: commercial genre literature is a formulaic kind of discourse, enabling easy production and consumption in an era of industrialized mass culture. However, even Kardos's diagram does not follow this logic. It features The Haunting of Hill House as its closest illustration of the "genre" section, far from the literary recognition of William Faulkner's The Sound and the Fury. The Haunting of Hill House is a 1959 ghost story; it checks the "stuff" criterion; it sits halfway between "easy" and "difficult," thus straddling the high-brow/low-brow divide; but it was also a finalist for the 1959 National Book Awards, whose mission is to "celebrate the best of American literature, (...) and to enhance the cultural value of good writing in America."1 The book is therefore both part of the lowbrow genre section for marketing purposes, and a celebrated part of the canon of $20^{\text {th }}$ century American literature.

Other examples from this diagram humorously reveal the intrinsic ambiguity of the two meta-genres (is Salman Rushdie's The Satanic Verses not a work of literature?), which brings us back to Derrida's rejection of the oppressive "law of genre": texts and discourses participate in, rather than belong to, a genre, and the "mark" of genre does not betray the essence of a text but simply signals a referential relationship to preexisting conventions and practices. Thus generic games become an intrinsic part of literary creativity when authors deliberately rely on generic ambiguity or parody stereotypical generic traits to engage with contrasting traditions and unsettle their readers' expectations. Yet such ambiguities also lead to potentially conflicting interpretations, and we now need to examine those discrepancies. Since some genres are recognizable thanks to their closeness to cognitive-prescriptive models and conventions, what do misunderstandings tell us about genre? What do pragmatic and cognitive discrepancy suggest about the elusive nature of genre as a working concept in discourse analysis and literary criticism? The following cases caused generic issues at the time of their broadcast/publications, with far-reaching consequences.

\section{Orson Welles and The war of the worlds: mars attacks!}

Orson Welles's 1938 radio broadcast of The War of the Worlds is sometimes called a hoax, when it was in fact an explicit fiction, erroneously taken for a real-life news report on an invasion of the United States by aliens. Welles adapted British author H. G. Wells's 1898 novel about the invasion and rule of Southern England by the Martians. Wells, who also wrote The Invisible Man, The Time Macbine, and The Island of Doctor Moreau, is now considered a father of the science-fiction genre. When The War of the Worlds came out, however, the genre did not exist as such, and his novel was

\footnotetext{
${ }^{1}$ National Book Foundation, http://www.nationalbook.org/aboutus_history.html\#.U9pn1ai34is, accessed July 31, 2014.
} 
called a "scientific romance" following the taxonomy of the time. Orson Welles adapted Wells's story to fit an hour-long program in the series The Mercury Theatre on the Air on the CBS network. He produced, directed and acted in the program, which was broadcast live on October $30-$ Halloween night. Welles changed the time and space setting of the fiction to make it a contemporary narrative set in New Jersey. As is now notoriously known, the story exceeded Orson Welles' expectations, and the next day, national and regional newspapers reported a wave of "panic" and "terror" in response to what they called Welles's shameful hoax and "fake radio war" (Campbell, 2010, p. 27). The reported panic was largely a myth created by the printed press, although the program did have a powerful effect on listeners, many of whom were left badly confused. An unusually large volume of calls was received that night in police stations, fire departments and local newspapers, from casual listeners enquiring about the generic status of the program: was it a news bulletin of a Martian attack near Princeton, New Jersey, or a powerfully enacted and particularly convincing piece of fiction? Such confusion leads us to our first question regarding Welles's "hoax": the role of literary adaptation in genre misunderstandings.

To adapt the novel for the radio and make it relevant to his contemporary American listeners, Welles transferred the story from late nineteenth century England to the fictional "Wilmuth farm", located in the (real) town of Grovers Mill, New Jersey, near Princeton University. The time of the story is in fact not exactly contemporary to listeners but set a year later, in 1939. The change of medium, from text to oral enactment, is of course crucial here, since radio broadcasting offers something that a book does not: it is immaterial, it enables actors to dramatize a text rather than simply read it, and it brings in sound effects. Welles had also banned adverts for the whole hour, thus allowing for a creative use of interruptions and interludes to maintain several layers of fiction within the program. The medium of radio also affects the chronological framing of fiction: even though Welles did announce the program as a fictional piece when he started, casual listeners tuning in mid-program would not have had the warning. Welles's first announcement is very clear: "The Columbia Broadcasting System and its affiliated stations present Orson Welles and the Mercury Theatre on the Air in The War of the Worlds by H. G. Wells" (opening sequence). Perhaps conscious of the ambiguity that might have been generated by his convincing reading, Welles inserted another warning forty minutes into the program:

You are listening to a CBS presentation of Orson Welles and the Mercury Theatre on the Air in an original dramatization of The War of the Worlds by H. G. Wells. The performance will continue after a brief intermission. This is the Columbia Broadcasting System.

Finally, Welles concluded the program with a general disclaimer, urging listeners to remain aware of the difference between reality and fiction:

This is Orson Welles, ladies and gentlemen, out of character to assure you that The War of The Worlds has no further significance than as the holiday offering it was intended to be. The Mercury Theatre's own radio version of dressing up in a sheet and jumping out of a bush and saying Boo! 
While those three announcements correspond to the pragmatic contract established with readers in written literature, the dramatization and direct address of the radio collapses narrative frames and bypasses the other conventions of written fiction: narration becomes enactment, without the reassuring visual space of a book or a stage. Welles's use of the present tense of live description further confused listeners: the program was structurally - if not thematically - realistic, not formally distinct from an actual news report. This seeming lack of fictional framing was what the printed press blamed Welles for, suggesting that his "fake story" was intentional deceit, and therefore a form of social transgression to be punished.

The program made use of simulated news bulletins, borrowing from a genre familiar to American audiences. The fictional "on-the-scene" reports of the alien ship also made creative use of a familiar trope in news-radio programming. Using such familiar genres in a fictional context was indeed unprecedented, so that listeners had no fictional expectations when faced with the "news flashes" that punctuated the program. The historical context was also instrumental in creating a panic among some listeners: this was October 1938. America was following the ongoing war scares in Europe. During this very tense period, listeners had become accustomed to news bulletins interrupting entertainment programs with war news, first with the Anschluss in March, and then with Germany marching into Sudetenland on October first. To say that listeners were ripe and ready for an invasion story would be an understatement; whether Orson Welles used the historical context to his advantage and for an extra dose of realism is not known, but he certainly drew inspiration from it in writing his Alien script. By collapsing all narrative levels into one and inserting pretend "bulletins" within his narrative, Welles did more than call for his listeners' suspension of disbelief, he forced it. His final remarks on the fictional status of texts are all the more significant:

We annihilated the world before your very ears, and utterly destroyed the C. B. S. You will be relieved, I hope, to learn that we didn't mean it, and that both institutions are still open for business. So goodbye everybody, and remember the terrible lesson you learned tonight. That grinning, glowing, globular invader of your living room is an inhabitant of the pumpkin patch, and if your doorbell rings and nobody's there, that was no Martian ... it's Halloween.

Here, Orson Welles suggests that the effects of fiction are powerfully real: fiction elicits excitement, terror or laughter in its audience; this, however, does not mean that fiction is a form of deceit, contrary to what the newspaper claimed the next day.

Although there were no public disturbances of any sort, Welles was subjected to a violent media backlash immediately after his program was broadcast. This brings us back to the normative dimension of the "laws" of genre, and to the politics of genre. While the newspaper relished the sensationalism of their panic stories - thus reminding us that journalistic narratives often borrow heavily from sensationalist fiction - they very strongly condemned Orson Welles, and called for stronger censorship and regulation of the discursive genres broadcast on the radio. The New York Times, among others, chimed in: 
In the broadcast of the The $W$ ar of the Worlds blood-curdling fiction was offered in exactly the manner that real news would have been given and interwoven with convincing actualities... Radio officials should have thought twice before mingling this new technique with fiction so terrifying (Campbell, 2010, p. 42).

However hypocritical the newspapers were, their reactions showed that Welles had overstepped a number of implicit generic boundaries. In 1938, radio was a very popular medium, albeit still relatively young - the CBS network had started only 10 years earlier. The radio-versus-newspaper rivalry goes back to the 1920s but tensed in the 1930s, when radio took the lead in news reporting thanks to its ability to communicate breaking news instantly, especially during the 1938 war scares. Following Orson Welles's broadcast, a few individuals attempted legal actions (one sued CBS for causing "mental anguish"), but none were successful. The most significant backlash came from official censorship: "Federal Communications Commission chairman Frank McNinch quickly obtained informal agreement from the radio networks that fictional news "flashes" would not be used again" (Pooley and Socolow 2013, online). Ultimately, Pooley \& Socolow suggest, the "panic myth" surrounding Welles's The War of the Worlds serves as a cautionary tale warning us of the power of media over our lives. More importantly, I would argue, the story is a tale of two genres and a lesson in genre politics.

First, genre is related to both thematic content and the structural form of discourses or texts. Welles's alien story leans towards science fiction, while its use of "flash bulletins" pulls it towards journalistic discourse and therefore (since his narrative does not correspond to reality), towards deceptiveness: it becomes a "hoax." Secondly, literary adaptations transform genres, in this case from prose fiction to drama, with the added discrepancy of written narrative vs. broadcast speech. This results in confusion and misunderstanding, or, depending on your point of view, in the successful game of make-believe that is convincing fiction. Thirdly, generic ambiguity is related to pragmatic expectations: the audience does not recognise Welles's piece as science fiction because is contradicts their primary use of the radio as a news source. Playing with the generic features of narratives therefore means transforming a relatively stable horizon of expectation for the users of genre. The various reactions elicited by the original 1938 broadcast reveal the different degrees of genre literacy throughout society, thus exposing a social divide between those "in the know" and those without access to the conventions and techniques of literary genre-bending. In the American context of the 1930s in which identity is largely about recognition, misunderstanding (i.e. not recognising) genres has political and social consequences: Welles was accused of being unpatriotic for confusing his fellow citizens in a time of trouble. Finally, Welles's radio broadcast exposes genre as part of the production and consumption of mass communication, and therefore as a crucial player in social, political, and economic human relations.

Orson Welles's adaptation was called a hoax when it was in fact a sincere piece of fiction: rather than a deliberate faking of genre, it can be considered a case of misunderstanding related to genre literacy. Let us now turn to a case of deliberate misleading: when genre is voluntarily subverted in order to deceive its users. Alan 
Sokal's 1996 academic article, aptly and no doubt ironically titled "Transgressing the Boundaries," is one such case.

\section{Conclusion: "Transgressing the boundaries: towards a transformative hermeneutics of quantum gravity."}

In 1996, New York University Professor Alan Sokal published an article in the academic journal of post-modern cultural studies Social Text (1996: 217-252). His article was entitled "Transgressing the boundaries: towards a transformative hermeneutics of quantum gravity" and is still available online. According to Sokal himself, the article was deliberately full of errors and unsubstantiated argumentation. Calling for "progressive" science and arguing against the "patriarchal" and "reactionary" nature of mathematics, Sokal's article challenged mathematical science as politically and ideologically motivated, eventually questioning the validity of notions such as objective reality and mathematical logic altogether. The article concludes thus:

(...) a liberatory science cannot be complete without a profound revision of the canon of mathematics. As yet no such emancipatory mathematics exists, and we can only speculate upon its eventual content. We can see hints of it in the multidimensional and nonlinear logic of fuzzy systems theory; but this approach is still heavily marked by its origins in the crisis of late-capitalist production relations. Catastrophe theory, with its dialectical emphases on smoothness/ discontinuity and metamorphosis/unfolding, will indubitably play a major role in the future mathematics; but much theoretical work remains to be done before this approach can become a concrete tool of progressive political praxis. Finally, chaos theory - which provides our deepest insights into the ubiquitous yet mysterious phenomenon of nonlinearity - will be central to all future mathematics. (1996, p. 252)

Sokal imitates the style and common tropes of deconstructionist cultural theory and contemporary American literary criticism. This should therefore be considered a parody, but it was not recognised as such by the editors of Social Text, who selected and published the article as a serious piece, taking its message literally. Only with hindsight, then, can we label this text a parodic piece. On the other hand, any physicist or mathematician would have identified the article as a fake, which brings us back to the determination of a genre community. The success of Sokal's hoax relied entirely on its restrictive understanding of "genre community": the experts reading and editing his piece were not experts in the field of mathematics, and simply assumed the sincerity of the author, following the basic principles of cooperative communication. Two reasons can explain the editors' mistake regarding the article's contents: first, the excessive specialisation of academic disciplines makes it more difficult for publishers to find competent readers for every article they publish. This paves the way for potential errors. Second, as Sokal suggested in the midst of the "affair," publishers are often sensitive to their prospective authors' status: a tenured Professor at NYU has better chances of being published regardless of the intrinsic quality of his production. 
As a speech act, Sokal's article thus denounces the weaknesses of an excessively restrictive genre community.

Sokal revealed his hoax in the May/June issue of Lingua Franca, a journal focusing on academic life and debates in the United States, shortly after Social Text published his article. Significantly, he regards his piece as an "experiment":

I decided to try a modest (though admittedly uncontrolled) experiment: Would a leading North American journal of cultural studies - whose editorial collective includes such luminaries as Fredric Jameson and Andrew Ross - publish an article liberally salted with nonsense if (a) it sounded good and (b) it flattered the editors' ideological preconceptions?" (1996, online)

For Sokal, the piece was an explicit parody, recognisable as such by any competent physicist or mathematician, but "evidently, the editors of Social Text felt comfortable publishing an article on quantum physics without bothering to consult anyone knowledgeable in the subject." Sokal then describes his article as an assemblage of postmodernist quotes strung together without argument: "one finds only citations of authority, plays on words, strained analogies and bald assertions." For Sokal, this clearly summarizes a specific genre, that of deconstructionist philosophy and post-modern American cultural studies.

Sokal's hoax sparked long-running debates in newspapers and academic journals from both sides of the Atlantic, including Lingua Franca, Dissent, Tikekun, Le Monde, and Physics Today. This in turn prompted follow-ups in book form: Fashionable Nonsense (1998) and Beyond the Hoax (2008). The intensity of the debate is in my view not simply a case of academic war (an old genre in itself); it stems from the threatening nature of the hoax to the genre of academic writing as a whole. Sokal's hoax contains two separate speech acts: the deceitful submission of the text, and the contents of the text itself. According to the editors of Social Text, the fact that Sokal was not serious when he submitted his article is not relevant: the text itself carried an intrinsic intellectual value regardless of its author's overall intentions. More importantly, Sokal's article questions the relevance of genre itself: it plays on the expectations and preconceptions of a specific genre community to show how overly strong formal generic conventions affect our ability to follow the common principles of relevance and cooperative communication. It also raises the question of the generic features of a parodic text, both literally and pragmatically. Can Sokal's article be called a parody if it is not recognised as such? Finding the generic features of such hoaxes brings us to the distinction between serious and non-serious discourse. From a literary point of view, textual hoaxes can be considered a tradition, from Swift's 1729 Modest Proposal to Beckett's 1930 paper "Concentrism and Jean Du Chas" at Trinity College Dublin, we are faced with spoofs and parodies that entertain or challenge but do not fool their audiences.

Throughout the course of this paper, I have examined what makes genre literacy a social question involving communities and social norms of acceptability. My final remarks will leave some of these questions open. The generic features of "hoaxes" seem to reside solely in the pragmatic strategy and context of their production, since they formally imitate other genres. Alan Sokal's perception of genre 
is clearly one of stereotypical formats, as opposed to an examination of textual and discursive contents. His purely formal definition of genre leads me to a final experiment, that of The Postmodernism Generator. The Postmodernism Generator is an automatic system generating random texts from recursive grammars. ${ }^{2}$ It can be viewed as a form of automatic parody, favouring form over substance, the end-result being often nonsensical. The Generator provides a meta-textual comment on the generic features of post-modernist theory, and more generally, on all generic traits in texts and discourses. Automatically generated texts are a form of industrialized production in which the practices and conventions of genres are converted into mathematical constraints. The successes and failures of such designs both denounce the rigidity of genre conventions and fail to acknowledge the subtlety and range of generic discourse, leaving us with our initial ambiguity and the undefinability of genre.

\section{Bibliography}

BLANCHOT, M., 1959, Le livre à venir, Gallimard, Paris.

Campbell, W. J., 2010, Getting it Wrong: Ten of the Greatest Misreported Stories in American Journalism, University of California Press, Berkeley.

FOLEY, W. A., 1997, Anthropological Linguistics, Blackwell, Oxford.

DERrIDA, J., 1980, “The law of genre”, Critical Inquiry, 7, n¹, p. 55-81.

GEWIRTZ, P., 1996, “On 'I know it when i see it'”, Faculty Scholarship Series, Paper 1706, $<$ http://digitalcommons.law.yale.edu/fss_papers/1706>

JOYCE, J., 1996 [1916], A portrait of the artist as a young man, Penguin Popular Classics, London.

KARDOS, M., 2012, "The literary/genre fiction continuum", The Huffington Post, <http://www.huffingtonpost.com/michael-kardos/literary-genre-fiction_b_1857639.html>

LANGaCKer, R. W., 2008, Cognitive Grammar, Oxford University Press, Oxford.

Martin, J. R. and Rose, D., 2008, Genre Relations: Mapping Culture, Equinox, London.

MCCRuM, R., 2001, “The end of literary fiction”, Guardian, <http://www.theguardian.com/ books/2001/aug/05/features.review1>

MiLLER, C., 1984, “Genre as social action”, Quarterly Journal of Speech, p. 151-167.

Pooley, J. and Socolow, M., 2013, "The myth of the war of the worlds panic", Slate, $<$ http://www.slate.com/articles/arts/history/2013/10/orson_welles_war_of_the_worl ds_panic_myth_the_infamous_radio_broadcast_did.html $>$

SCHAEFFER, J.-M., 1995, "Genres littéraires”, in Ducrot O. et Schaeffer J.-M., Nouvean Dictionnaire Encyclopédique des Sciences du Langage, Seuil, Paris, p. 626-637.

SOKAL, A., 1996, "Transgressing the boundaries: towards a transformative hermeneutics of quantum gravity", Social Text 46/47, p. 217-252, <http://www.physics.nyu.edu/sokal/ transgress_v2/transgress_v2_singlefile.html>

2 http://www.elsewhere.org/journal/pomo/, accessed July 31, 2014. 
SOKAL, A., 1996, "A physicist experiments with cultural studies", Lingua Franca, $<$ http://linguafranca.mirror.theinfo.org/9605/sokal.html>

Swales, J., 1990, Genre Analysis, Cambridge University Press, Cambridge.

Welles, O., 1938, The War of the Worlds Radio Broadcast, <https://archive.org/details/ OrsonWellesMrBruns>

Wilson, D., and Sperber, D., 2006, "Relevance theory", in Horn L. R. and Ward G., The Handbook of Pragmatics, Blackwell, Oxford, p. 608-632.

WitTGenstein, L., 2001, Philosophical Investigations, 50th Anniversary Edition, Blackwell, Oxford. 